Supporting Information for:

\title{
Carbon Mineralization in Reactive Silicate Zones
}

Anne H. Menefee ${ }^{1}$ and Brian R. Ellis ${ }^{1 *}$

1. Department of Civil and Environmental Engineering

University of Michigan, Ann Arbor, MI, United States

*Corresponding author: 1351 Beale Ave, 167 EWRE

Ann Arbor, MI, 48109-2125

734-763-5470 (phone); 734-764-4292 (fax)

Email: brellis@umich.edu

\section{Table of Contents}

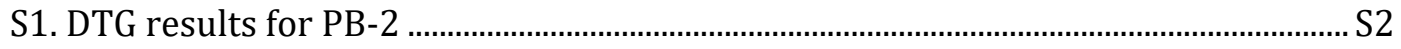

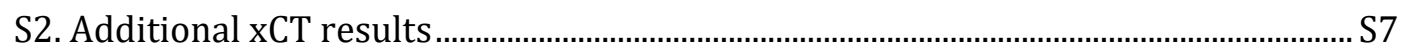

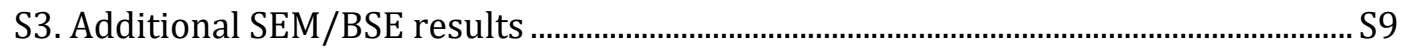

S4. Additional modeling results ...............................................................................................

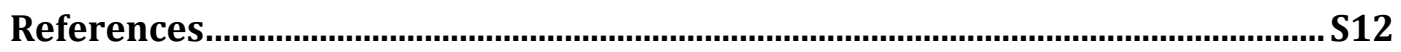

\section{List of Figures}

Figure S1 -Schematic overview of DTG sample locations....................................................... 2

Figure S2 - DTG curves for shorter fine-grained olivine bed...................................................S2

Figure S3 - DTG curves for longer fine-grained olivine bed................................................... 3

Figure S4 - DTG curves for shorter coarse-grained olivine bed.............................................. 3

Figure S5 - DTG curves for longer coarse-grained olivine bed................................................

Figure S6 - DTG curves for shorter mixed fine-grained olivine and wollastonite bed..............S4

Figure S7 - DTG curves for longer fine-grained olivine and wollastonite bed, top..................S5

Figure S8 - DTG curves for longer fine-grained olivine and wollastonite bed, base...............S5

Figure S9 - DTG curves for shorter coarse-grained olivine and wollastonite bed...................S6

Figure S10 - DTG curves for longer coarse-grained olivine and wollastonite bed...................S6

Figure S11 - Pre- and post-reaction xCT cross-sections for PB-1 …..................................... 7

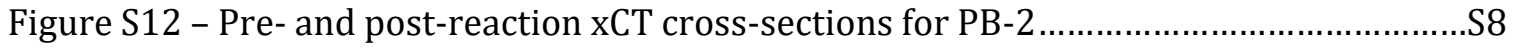

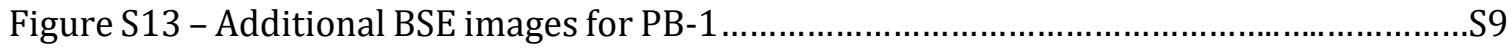

Figure S14 - Additional SEM images for PB-2 …........................................................... 10

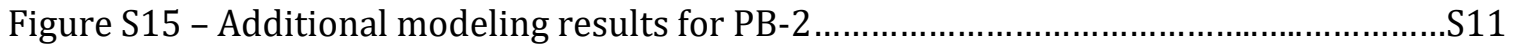




\section{S1. DTG results for PB-2}

DTG curves for each of the samples analyzed from PB-2 are included below. As discussed in the manuscript, one sample was taken from the shorter beds and two samples were taken from the longer beds (one from the upper half and one from the lower half). For clarity, the samples corresponding to each DTG curve (Figures S2-S9) are denoted in the schematic (Figure S1) below. Full DTG datasets are available upon request to the authors.

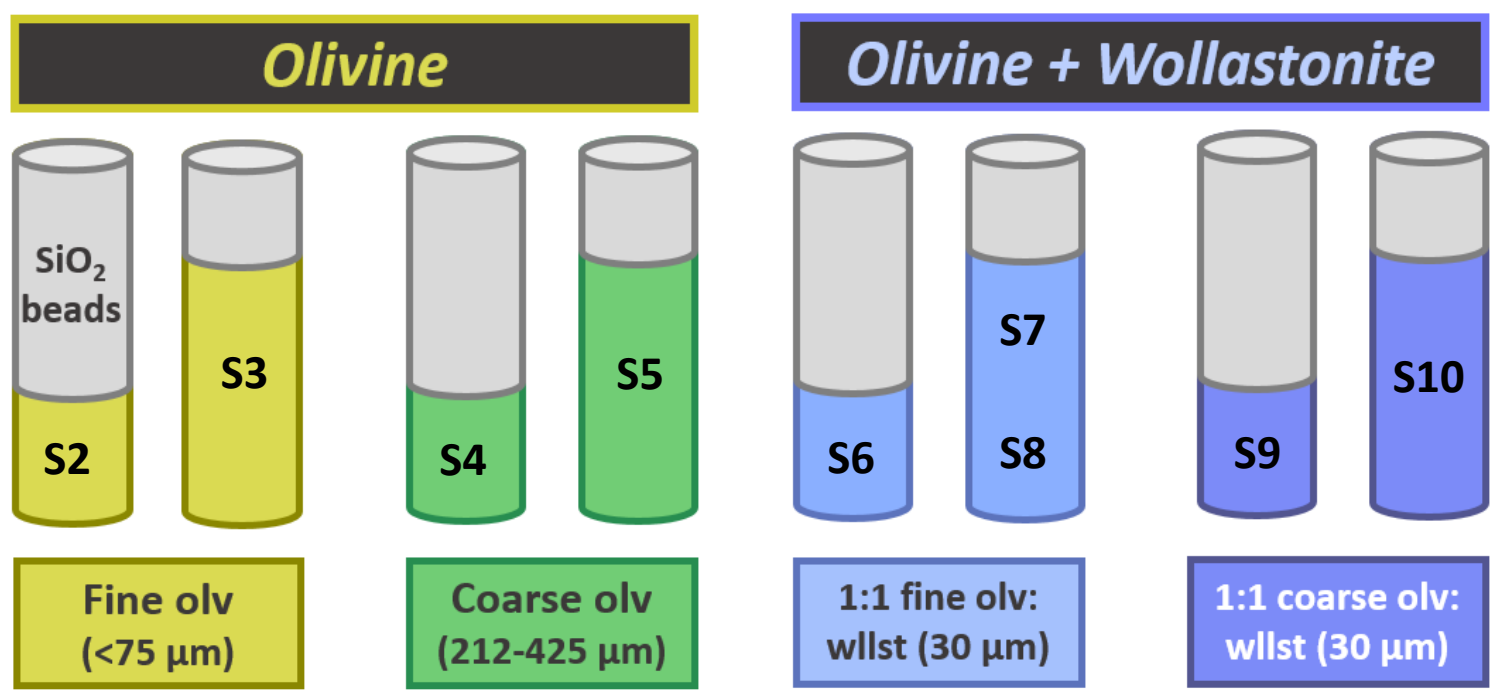

Figure S1. Overview of locations of DTG measurements presented in this section.

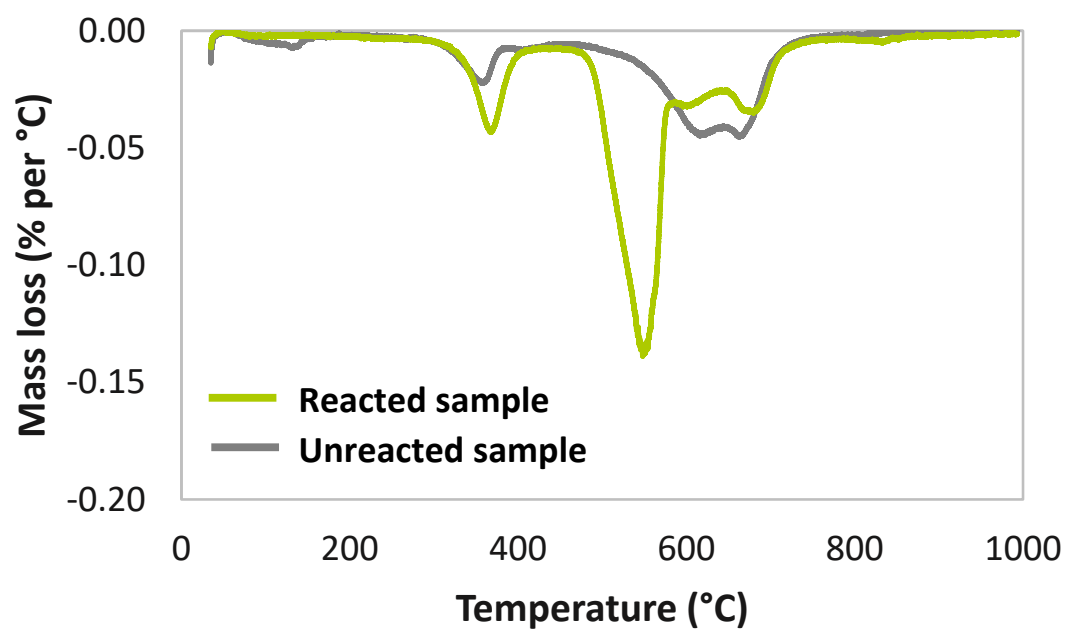

Figure S2. DTG curve for the reacted powders in the shorter fine olivine packed bed, compared to the unreacted fine-grained olivine powders. 


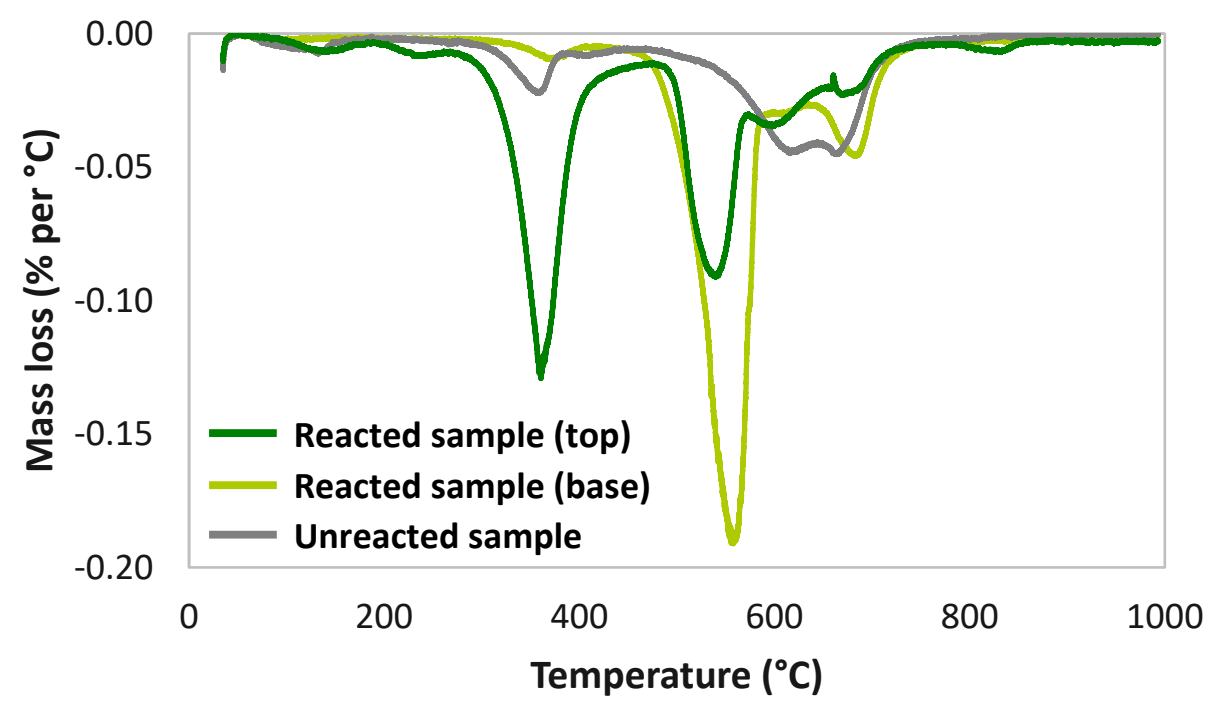

Figure S3. DTG curves for samples taken from the upper and lower halves of the longer finegrained olivine packed bed.

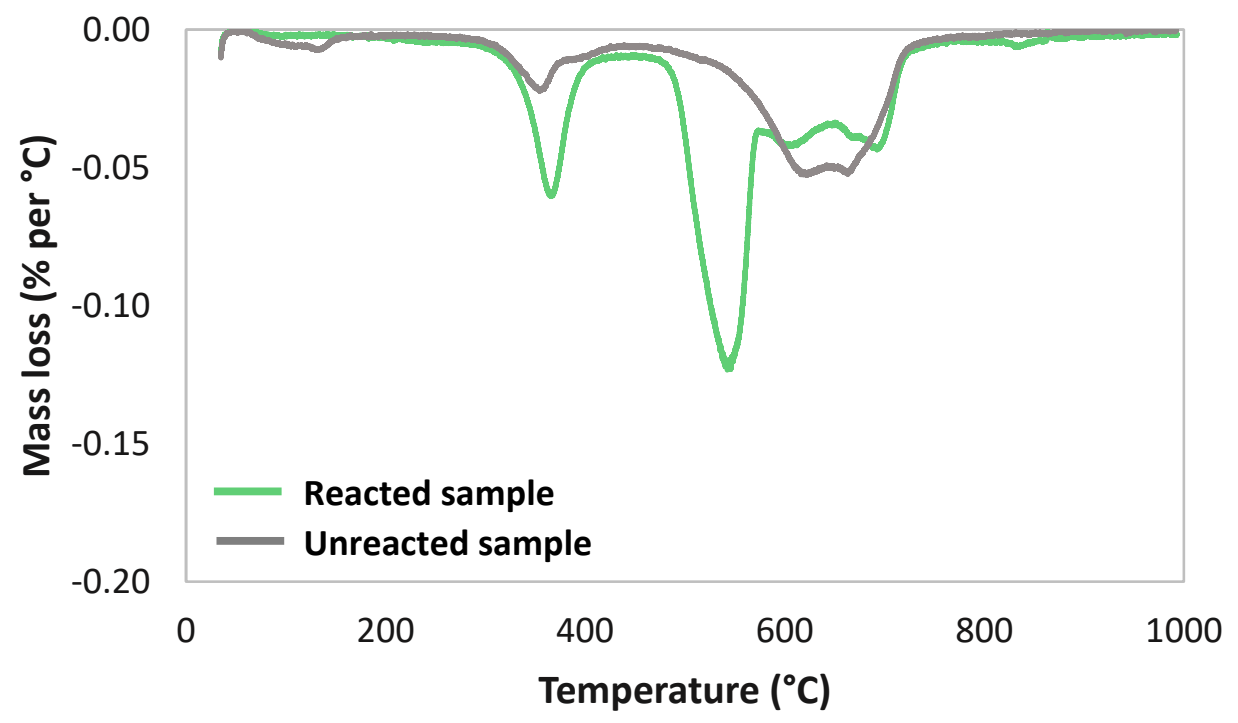

Figure S4. DTG curve and standard for the shorter coarse-grained olivine bed. 


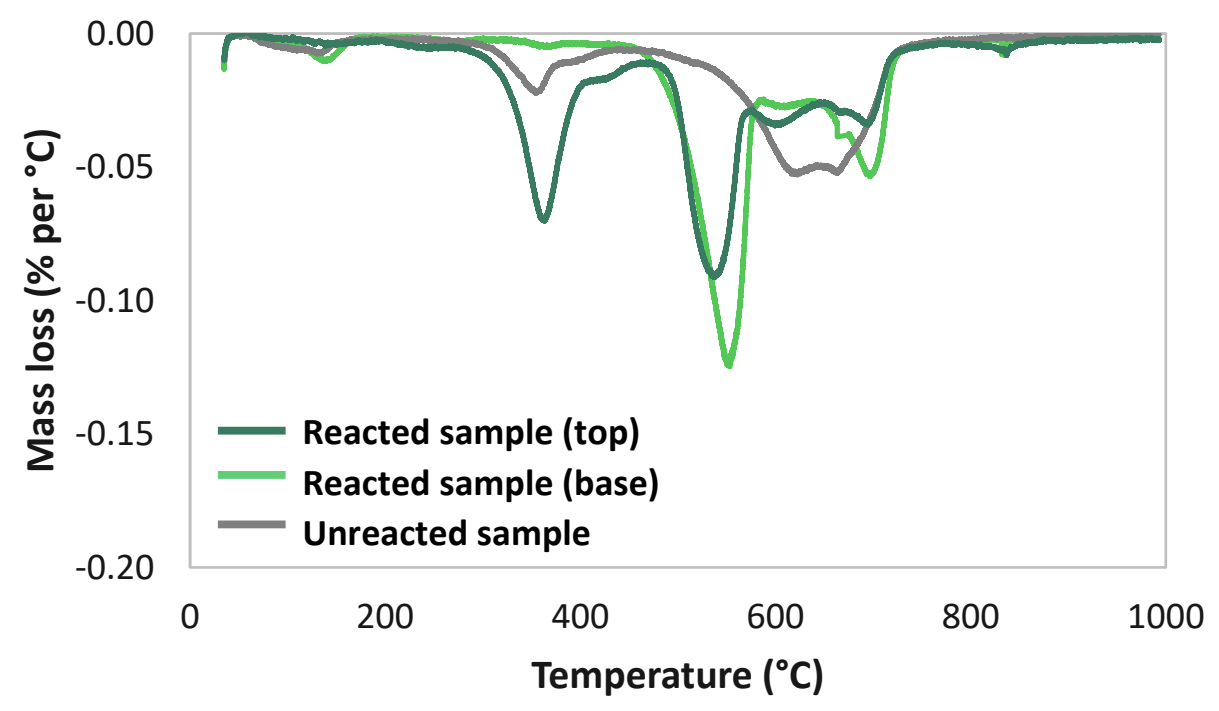

Figure S5. DTG curves for the longer coarse-grained olivine bed.

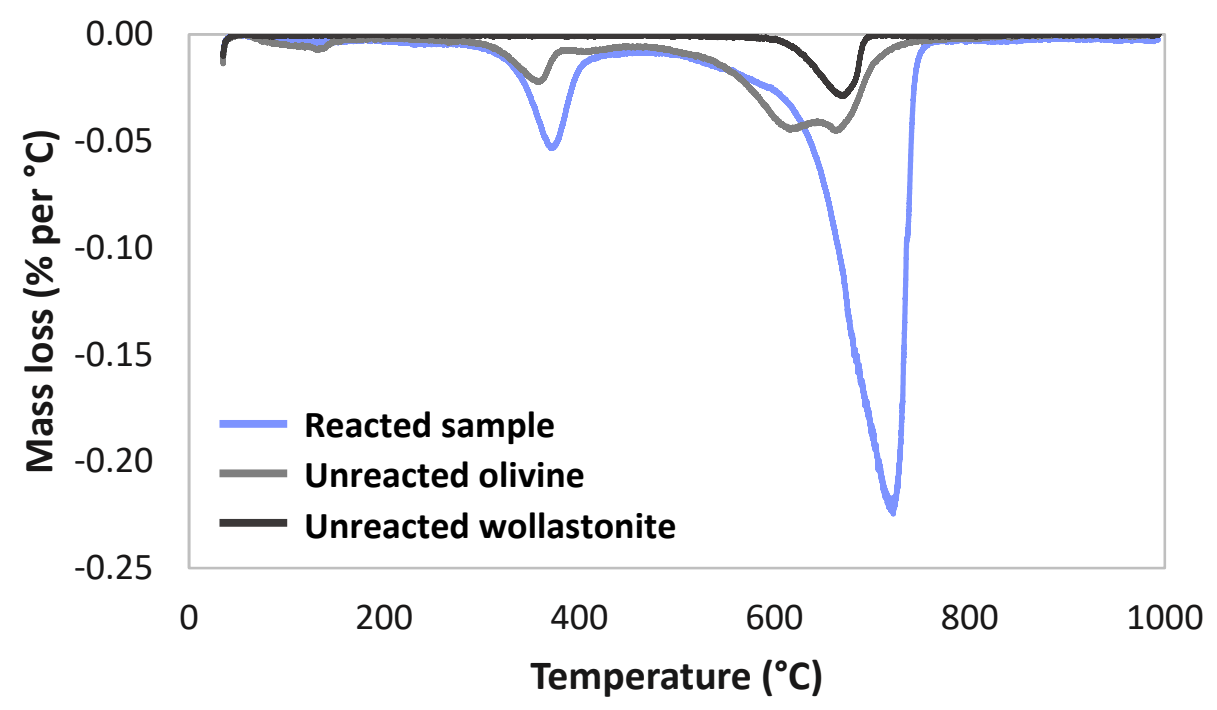

Figure S6. DTG curve for the reacted sample from the shorter mixed fine-grained olivine and wollastonite bed, compared to unreacted fine-grained olivine and wollastonite. 


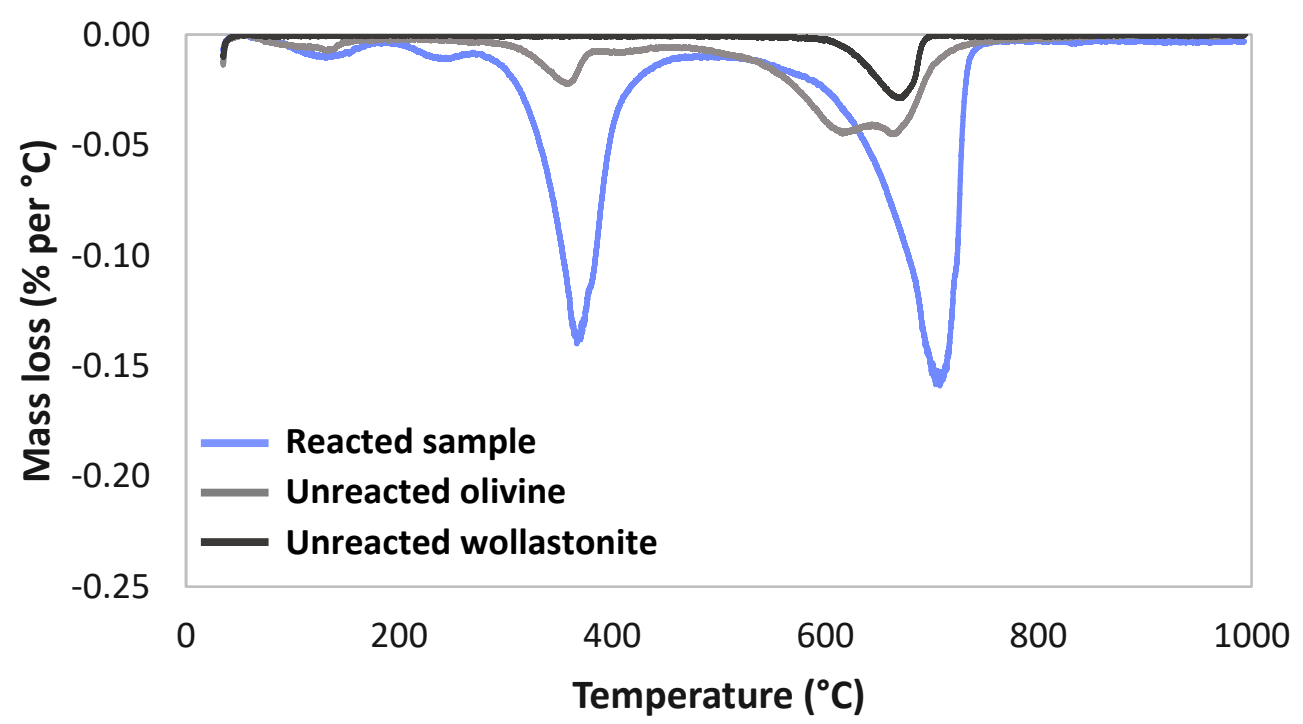

Figure S7. Reacted sample from the top half of the longer mixed fine-grained olivine and wollastonite packed bed, compared with unreacted olivine and wollastonite.

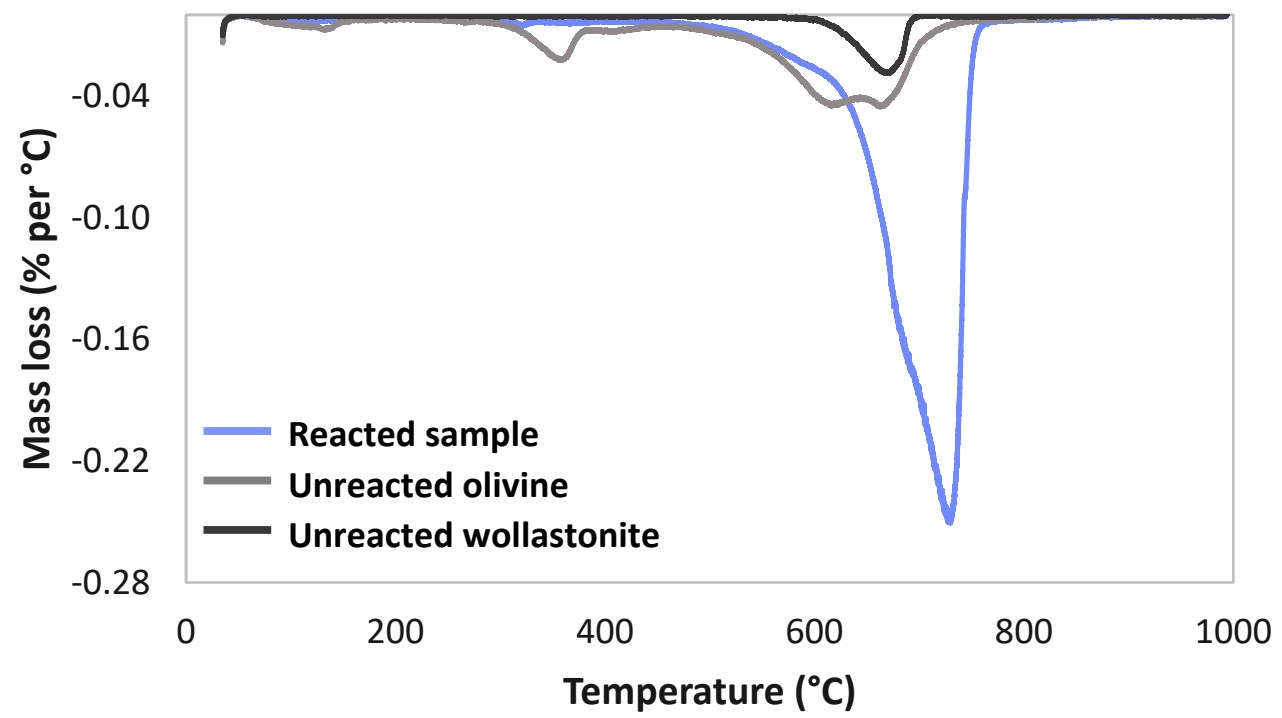

Figure S8. Reacted sample from the lower half of the longer mixed fine-grained olivine and wollastonite packed bed, compared with unreacted olivine and wollastonite. 


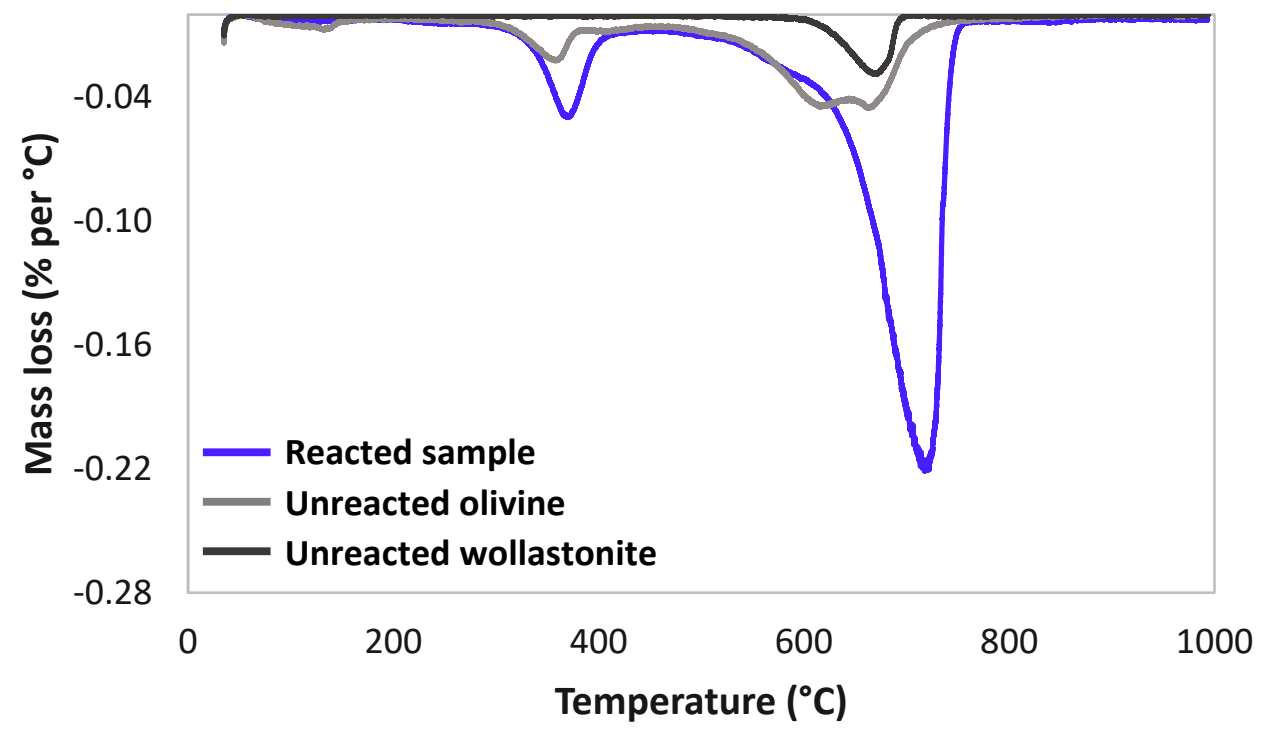

Figure S9. DTG curve for the reacted sample from the shorter mixed coarse-grained olivine and wollastonite bed, compared to unreacted fine-grained olivine and wollastonite.

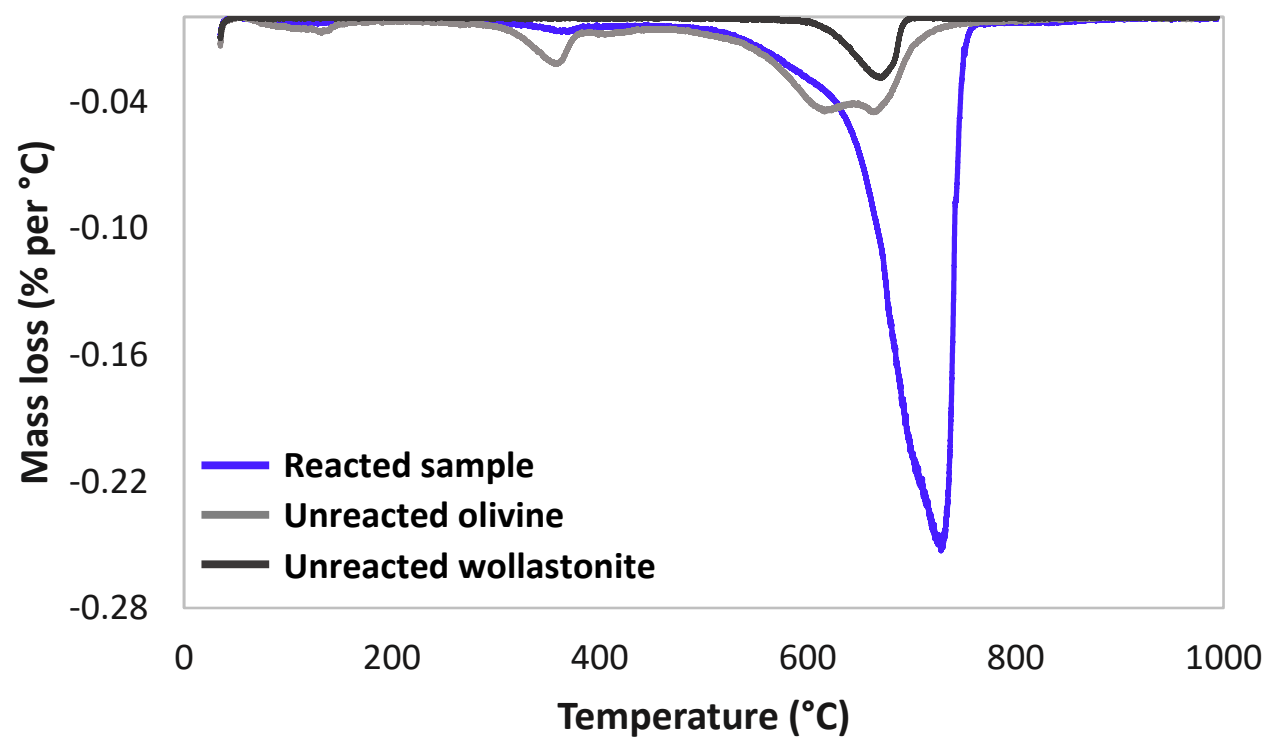

Figure S10. DTG curve for the reacted sample from the longer mixed coarse-grained olivine and wollastonite bed, compared to unreacted fine-grained olivine and wollastonite. As noted in the manuscript, only enough material for one TGA run was recoverable from this packed bed, precluding separate measurements for the upper and lower halves. 


\section{S2. Additional xCT results}

Comparisons of processed pre- and post-reaction xCT scans for both experiments are provided in this section. As noted in the manuscript, the scans from PB-1 were segmented to quantify changes in void space, but the scans from PB-2 could not be meaningfully segmented due to limited contrast between the starting minerals and reaction products along with the fact that most of the porosity was sub voxel resolution.
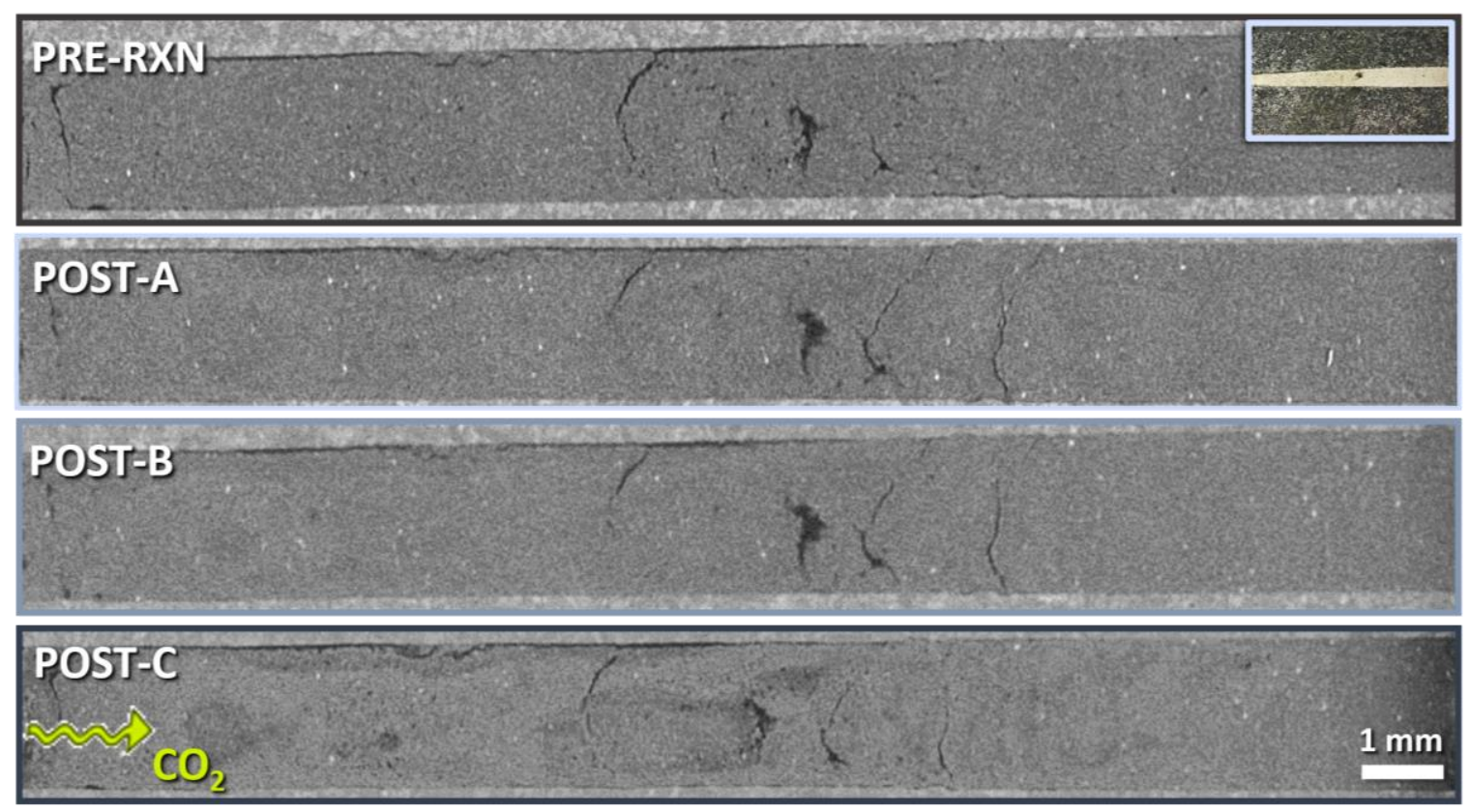

Figure S11. Cross sections taken through the center of the packed bed in PB-1 (shown in the inset at the upper right-hand corner) at each stage of the experiment. Refer to Section 2.2 for experimental details. The source of initial $\mathrm{CO}_{2}$ exposure in the packed beds is on the lefthand side of the cross-sections, as illustrated in the lower panel. 


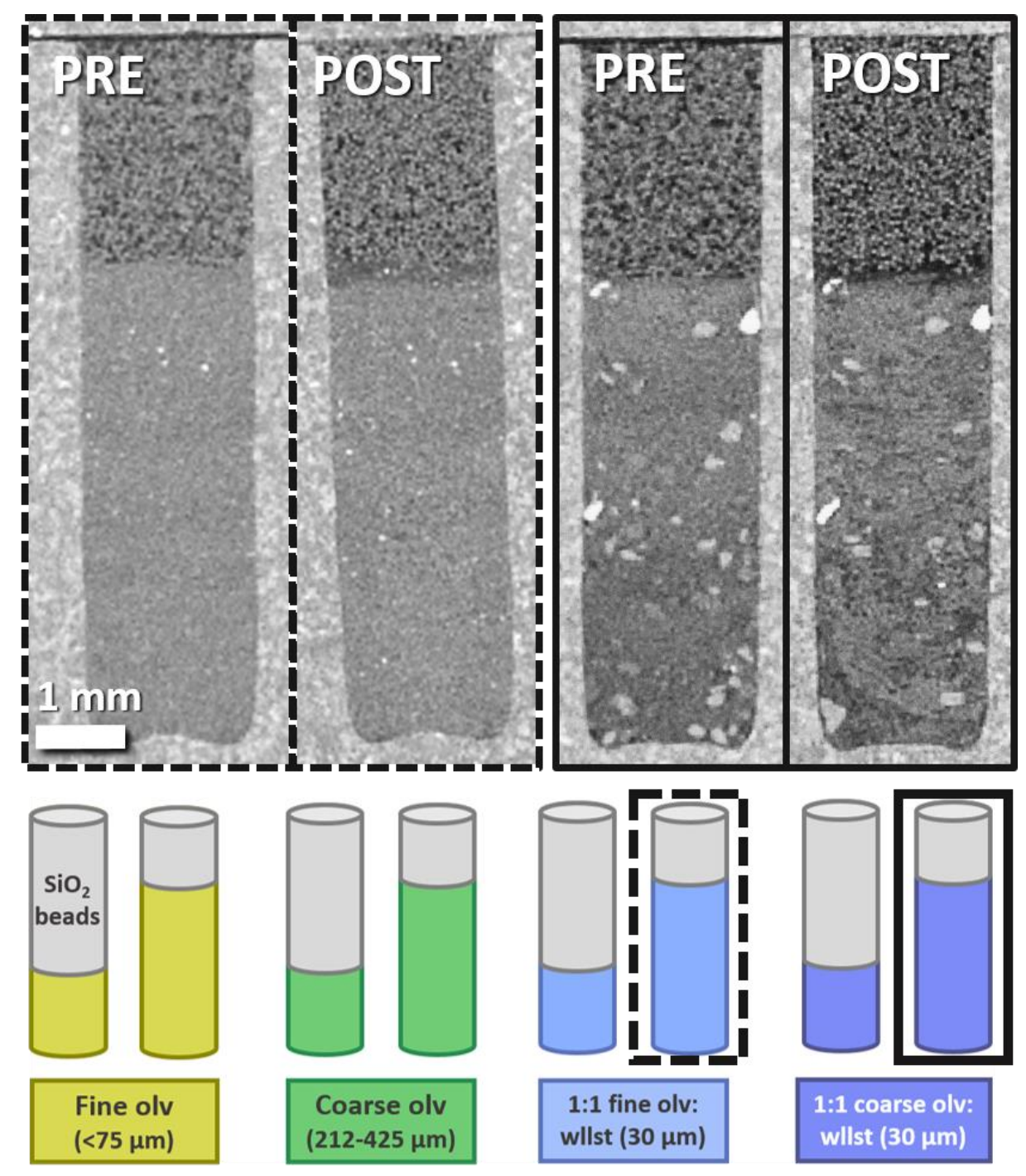

Figure S12. Comparison of pre- and post-reaction xCT scans for longer mixed beds with wollastonite and fine-grained olivine (left) or coarse-grained olivine (right), as denoted in the lower schematic. The 2D sections shown were taken through the center of the packed beds, parallel to the direction of flow. 


\section{S3. Additional SEM/BSE results}

Example BSE images from the reacted packed olivine/wollastonite bed in PB-1 are included in Figure S13 below. EDS maps are excluded because the reacting (olivine and wollastonite) and precipitating phases were so small that contrast in key elements (Ca, $\mathrm{Mg}$, Si) was limited. However, as documented in the manuscript, TGA revealed that significant $(>50 \%)$ carbonation occurred throughout the packed bed and most carbonates were identified as $\mathrm{CaCO}_{3}$, both in the form of calcite and aragonite, via Rama spectroscopy. Some Mg-bearing Ca-carbonates were also identified, primarily near the inlet of the packed bed.
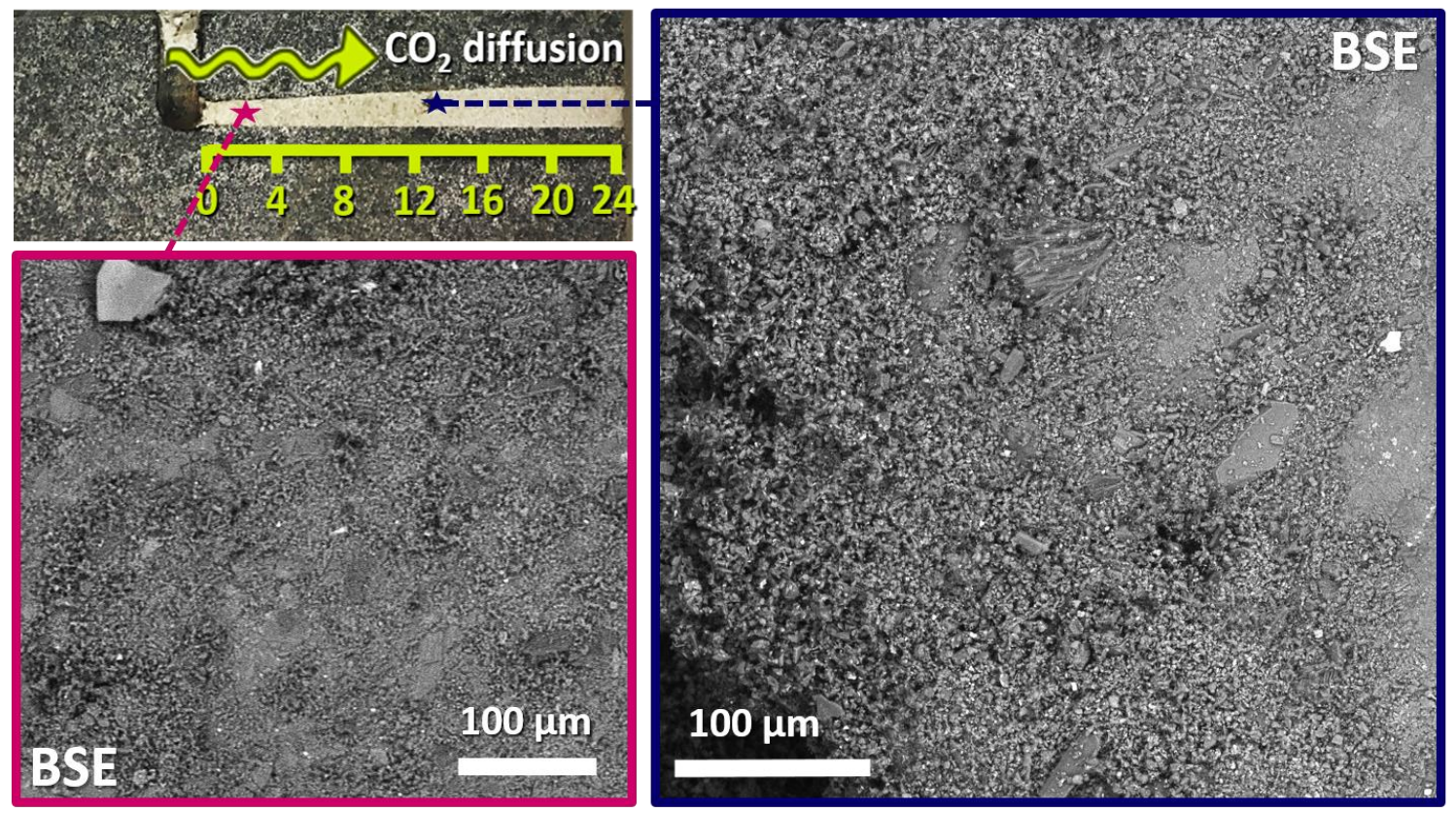

Figure S13. BSE images taken near the inlet and center of the packed bed in PB-1, which contained mixed wollastonite and fine-grained olivine. While SEM/EDS resolution was insufficient for mineral identification, most reaction products were identified as Cacarbonates with TGA and Raman spectroscopy. 
Figure S14 below includes SEM images from the deeper mixed wollastonite/coarsegrained olivine packed bed in PB-2 that highlight wispy Mg-silicate alteration products that formed during the experiment. These reaction products exhibit morphologies similar to chrysotile, an Mg-rich serpentine $\left(\mathrm{Mg}_{3}\left(\mathrm{Si}_{2} \mathrm{O}_{5}\right)(\mathrm{OH})_{4}\right)$ and naturally occurring form of asbestos. While many of these regions exhibited Raman peaks characteristic of Mg-serpentine, the precipitates were not explicitly identified because they formed as narrow fibers on the surface that were subject to background fluorescence and difficult to parse from underlying minerals with more defined crystal structures.
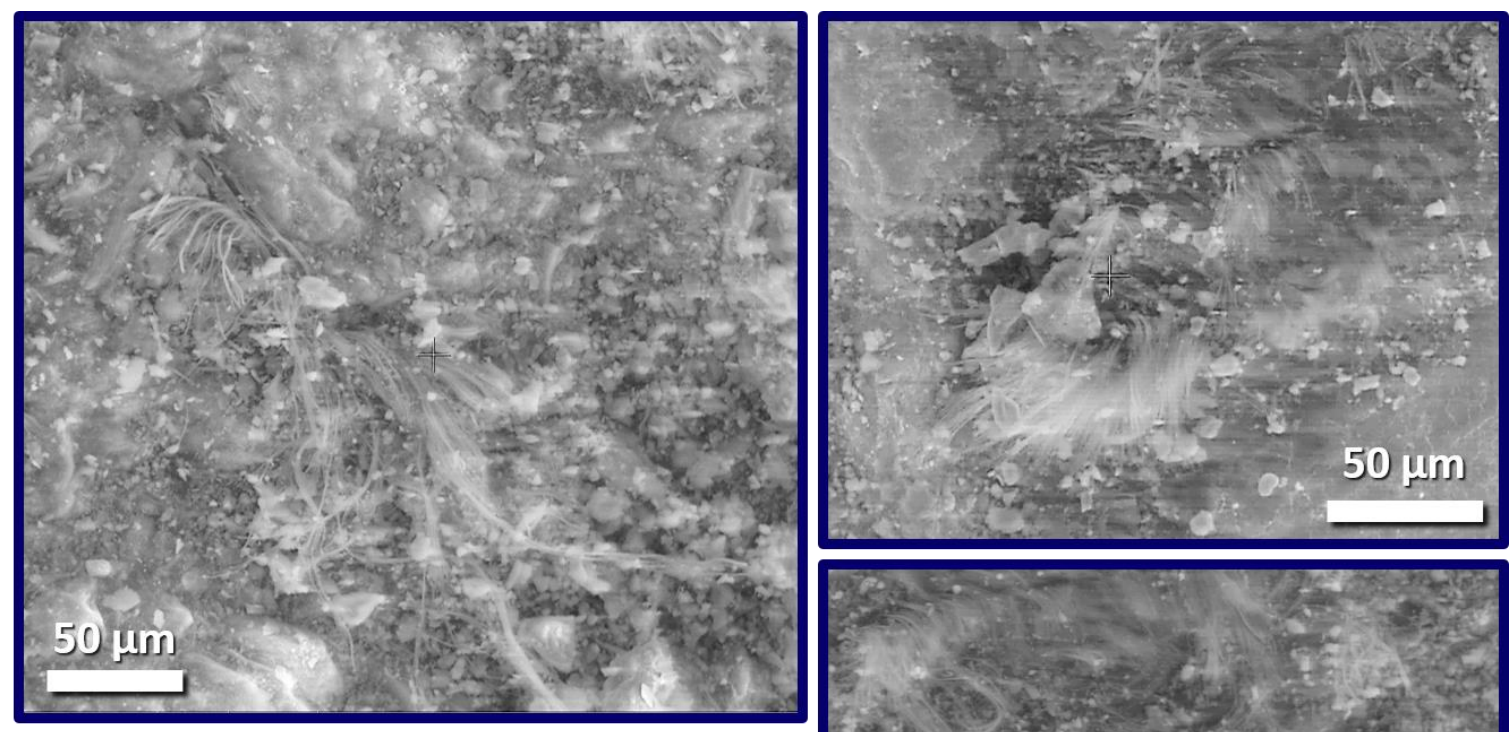

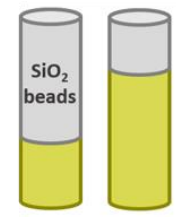

Fine olv $(<75 \mu \mathrm{m})$

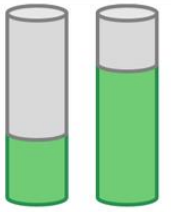

Coarse olv (212-425 $\mu \mathrm{m})$

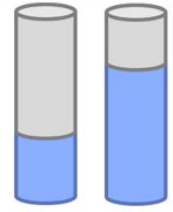

1:1 fine olv: wllst $(30 \mu \mathrm{m})$

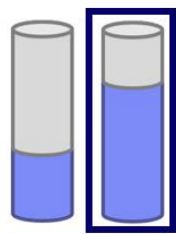

1:1 coarse olv: wilst $(30 \mu \mathrm{m})$

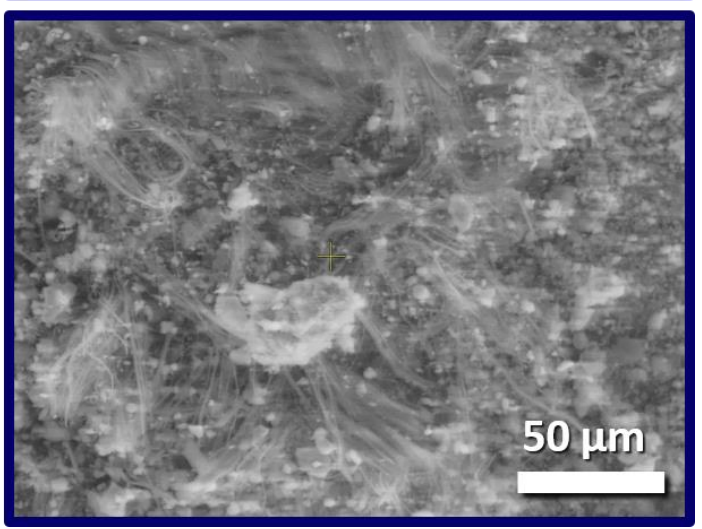

Figure S14. Additional SEM results from PB-2, highlighting fibrous Mg-rich silicate alteration products with morphologies and Raman spectra characteristic of Mg-rich serpentine. SEM images were taken from the deeper packed bed with mixed wollastonite and coarse-grained olivine, as denoted by the schematic in the lower left. EDS maps are excluded as they did not distinguish differences in key element $(\mathrm{Mg}, \mathrm{Si})$ abundances between the alteration products and underlying silicate minerals. 


\section{S4. Additional modeling results}

As discussed in Section 3.3 of the manuscript, additional simulations were run using the same conditions as the models created for the mixed wollastonite and coarse-grained olivine beds in PB-2, but with a coarser wollastonite with a specific surface area of $0.0069 \mathrm{~m}^{2} / \mathrm{g}$ (compared to $0.69 \mathrm{~m}^{2} / \mathrm{g}$ in the original models that simulated experimental conditions). Results comparing volume fractions of primary (forsterite and wollastonite) and secondary (antigorite and calcite) minerals throughout the modeled packed bed are presented in Figure S15 below.

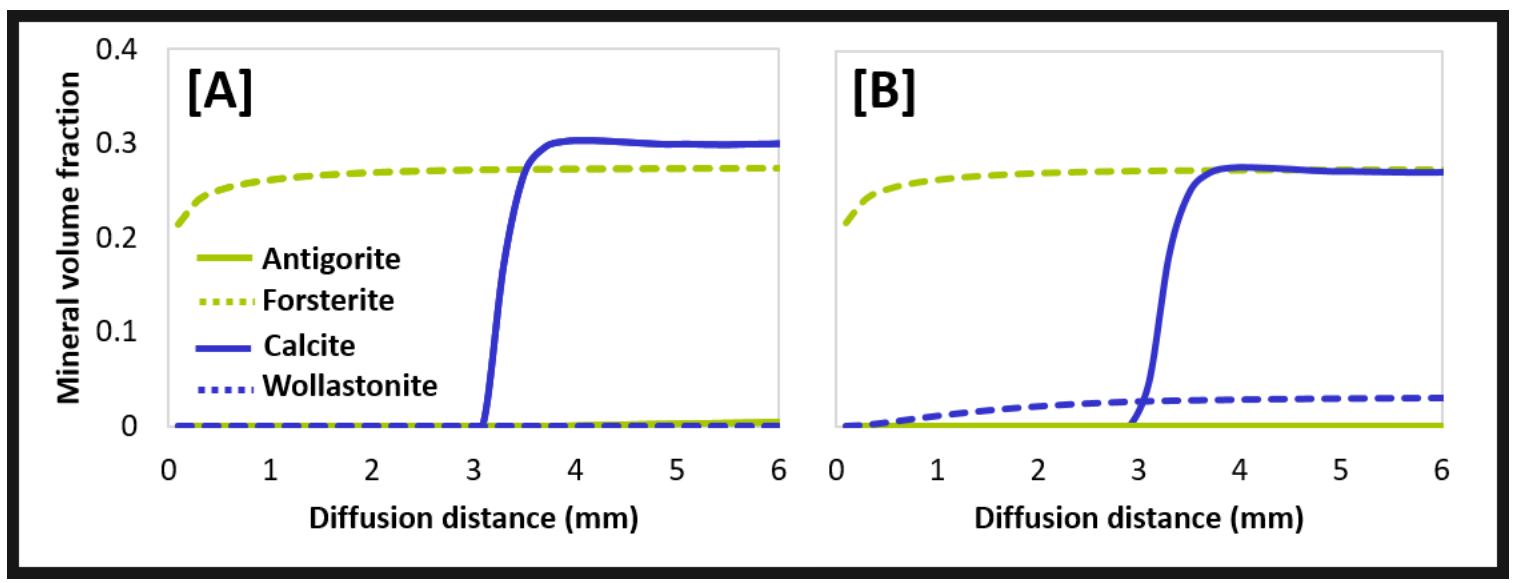

Figure S15. Reactive transport model predictions of mineral volume fractions as a function of diffusion distance into equivalent packed beds containing [A] fine-grained wollastonite with coarse-grained olivine (1:1 mixture) and [B] coarse-grained wollastonite and olivine in a 1:1 mixture. Dashed lines indicate primary (i.e. dissolving) minerals while solid lines represent secondary (i.e. precipitating) phases. 